\title{
BIBLIOTECÁRIOS E DOCUMENTALISTAS NA FRANÇA: origens e percursos da formação do profissional da informação
}

\author{
BIBLIOTHÉCAIRES ET DOCUMENTALISTES EN FRANCE: origines et \\ parcours de la formation du professionelle de l'information
}

Martha Suzana Cabral Nunes

UFS

\section{RESUMO}

Este artigo aborda o tema da formação dos profissionais da informação, em especial dos profissionais da informação franceses. $O$ objetivo é discutir e apresentar as nuances de formação do profissional da informação francês voltadas para a mediação da informação. A metodologia adotada foi a pesquisa exploratória e a pesquisa documental, e de abordagem qualitativa. Utilizou-se ainda a pesquisa bibliográfica e documental para análise de fontes primárias e secundárias. As observações feitas revelam a existência dos bibliotecários, dos documentalistas e dos professoresdocumentalistas como categorias diferentes atuando nas bibliotecas e centros de documentação na França. Espera-se que esse estudo contribua para a compreensão das origens e das influências na formação do moderno profissional da informação brasileiro.

Palavras-chave: Profissional da informação. Estudos franco-brasileiros. Formação profissional. Mediação da informação.

\section{RESUMÉE}

Cet article aborde la question de la formation des professionnels de l'information, en particulier les professionnels d'information français. L'objectif est de discuter et présenter les nuances de formation professionnel de l'information française axée sur la médiation d'informations. La méthodologie adoptée a été la recherche exploratoire et de recherche documentaire, et l'approche qualitative. Il a également été utilisé la recherche bibliographique et documentaire pour l'analyse des sources primaires et secondaires. Les observations révèlent l'existence de bibliothécaires, documentalistes et professeurs-documentalistes que sont différentes catégories de travail dans les bibliothèques et centres de documentation en France. Il est prévu que cette étude contribuera à la compréhension des origines et des influences dans la formation du moderne professionnel de l'information brésilien.

Mots-clés: Professionnel de l'information. Études franco-brésiliennes. Formation professionnel. Médiation de l'information. 


\section{INTRODUÇÃO}

Sabe-se que as unidades de informação, incluindo-se nesta categoria bibliotecas, arquivos e centros de documentação, são consideradas espaços por excelência para a disseminação da informação, onde profissionais e usuários estão em conexão direta, ligados pela informação, pelo desejo de se informar, de conhecer e de se conectar com o mundo.

A utilização de recursos tecnológicos tem sido um dos grandes motores nas últimas décadas para as mudanças de paradigmas no contexto das unidades de informação, assim como na própria constituição dos perfis profissionais, visto que é preciso acompanhar não apenas a evolução tecnológica, a qual ainda não dá sinais de esgotamento, mas também as alterações comportamentais que pesam sobre os usuários, que alteraram suas formas de acessar e utilizar a informação em seu dia a dia.

Nesse contexto evolutivo, os profissionais da informação são chamados a atuar de modo dinâmico e proativo, considerando-se que as demandas da sociedade exigem um novo posicionamento profissional, mais preparado para superar desafios e pronto a utilizar os recursos tecnológicos à sua disposição com sucesso.

Nos diferentes cantos do planeta são profissionais da informação aqueles indivíduos preparados para dialogar com os usuários a respeito de suas necessidades de informação e a buscar alternativas viáveis de acesso e uso da informação, a fim de que eles possam transpor a barreira do desconhecido e alcançar novos status, principalmente do ponto de vista social e educacional. Em outros países, enquadram-se nessa categoria os librarians, nos EUA e na Inglaterra, bibliothécaires no Canadá, bibliotekar na Dinamarca, e na França os bibliothécaires, os documentalistes e os professeurs-documentalistes.

Desse modo, este artigo abre esse estudo trazendo um recorte inicial que aborda a formação do profissional da informação francês no sentido de responder às seguintes questões: como se dá a formação do profissional da informação na França? Quais são as escolas que se ocupam dessa formação e como ela evoluiu ao longo do tempo?

O objetivo deste artigo é discutir e apresentar as nuances de formação do profissional da informação francês voltadas para a mediação da informação.

A metodologia adotada foi a pesquisa exploratória e a pesquisa documental, de abordagem qualitativa. Utilizou-se, ainda, a pesquisa bibliográfica e documental para análise de fontes primárias e secundárias. 
0 estudo justifica-se por sua relevância na medida em que apresenta detalhes da formação profissional na área da Ciência da Informação (CI) em países que já estabelecem relações de intercâmbio de pesquisa com o Brasil, a exemplo da França, que se destaca pela Rede MUSSI de pesquisadores Franco-brasileiros em Mediações e Usos Sociais dos Saberes e da Informação, cujas pesquisas interdisciplinares vêm sendo desenvolvidas desde 2008.

Observa-se que as preocupações das instituições francesas para uma formação profissional voltada para a mediação da informação ainda não são o centro das atenções, o que permite inferir que a mediação, em muitos casos, é aprendida no dia a dia profissional mais do que nas salas de aula.

\section{A FORMAÇÃO DO PROFISSIONAL DA INFORMAÇÃO PARA MEDIAÇÃO}

Ainda considerada um conceito recente e em discussão no campo da CI, a mediação da informação é um termo muitas vezes entendido no contexto da comunicação entre indivíduos, onde um fornece informação, e outro a recebe. Sabe-se, porém, que, no contexto da CI e diante das pesquisas que já avançaram nesse campo, a mediação vai além para explicitar um processo de interação, que não se dá de modo vazio de intenções nem de interferências, mas que tem em ambos os participantes a possibilidade de interação.

Nesse sentido, parte-se, nesse estudo, do conceito de mediação baseado em Almeida Júnior (2009, p. 92), que a entende como:

Toda ação de interferência - realizada pelo profissional da informação -, direta ou indireta; consciente ou inconsciente; singular ou plural; individual ou coletiva; que propicia a apropriação de informação que satisfaça, plena ou parcialmente, uma necessidade informacional.

Considerando a mediação da informação no contexto educacional baseada em Reuven Feurstein, Varela e Barbosa (2009) compreendem o conceito de multirreferencialidade de saberes que ocorre nos atos de mediação e, para isso, relacionaram o fenômeno do alfabetismo/analfabetismo como a multiplicidade de modos de olhar e analisar o mesmo fenômeno educativo, de maneira a não reduzi-lo em si mesmo, mas dando espaço para as diferentes dimensões e perspectivas que o cercam: "[...] ou seja, a multirreferencialidade entendida como uma pluralidade de olhares dirigidos a uma realidade, uma pluralidade de linguagens para traduzir esta mesma realidade e os olhares dirigidos a ela." (VARELA; BARBOSA, 2009, p. 200). 
Para o profissional da informação, as autoras ressaltam a necessidade de que ele esteja preparado para trabalhar com a pluralidade e a multirreferencialidade, e que seja capaz de interpretar as abordagens que cercam as diferentes áreas do conhecimento, a fim de que possa contribuir ativamente para o desenvolvimento de competências e habilidades nos usuários.

\begin{abstract}
Isto porque, como apoiadores do processo de transferência e usabilidade da informação, a qual vai subsidiar a construção e desconstrução do conhecimento, estes profissionais, na função de mediadores, precisam levar seus usuários a desenvolverem as habilidades do observar, do analisar, do transcender; criando pontes e conexões com o mundo exterior, vivenciando a interdisciplinaridade e a contextualização, imprescindíveis ao desenvolvimento, e a internalização de uma atitude científica, o que reafirma a necessidade destes profissionais, de modo específico, de conhecer as teorias cognitivas. (VARELA; BARBOSA, 2009, p. 201, grifo nosso).
\end{abstract}

Para atuar na educação dos usuários e com a mediação da informação, os profissionais da informação precisam ser preparados eles mesmos para essa tarefa, considerando-se que essa formação deve propiciar-lhes condições de desenvolvimento de competências não apenas técnicas, mas também culturais, intelectuais e cognitivas, que são cruciais para a efetiva difusão da informação, exigindo-se deles que saibam cada vez mais operar os estoques de informação e que saibam reconhecer no objeto com o qual trabalham - a informação - sua utilidade social.

Nesse sentido, Smit e Barreto (2002) destacam que a formação desse profissional deve contemplar a característica mutável da sociedade contemporânea, indo além da aprendizagem técnica e procedimental para alcançar a compreensão da informação, tanto de suas origens como também de seu fim social.

Para os autores, entender a base conceitual da CI oportuniza ao profissional da informação a capacidade de compreensão da dinâmica da informação na sociedade atual, com suas constantes mudanças tecnológicas e paradigmáticas, fazendo com que ele seja um profissional completo, capaz de atuar em diferentes espaços e contextos (SMIT; BARRETO, 2002).

Como debatido por Souza (1996), a formação do bibliotecário deve se dar não apenas no sentido de desenvolver-lhe competências técnicas, mas, além disso, competências que tornem sua relação com o público mais humana. Partindo-se da premissa de que cabe ao profissional da informação, em especial ao bibliotecário, como uma de suas funções primordiais, promover o acesso e a disseminação da informação, 
compreende-se que a sua formação deve estar pautada em um conjunto de conhecimentos que conduza ao desenvolvimento dessas competências, seja de modo teórico e também prático,

Dudziak (2001) destaca a mudança de foco no trabalho dos bibliotecários, direcionando suas atividades para o trabalho intensivo que leve à autonomia e à construção do conhecimento por parte do usuário. Essa visão deixa para trás uma preocupação apenas em prover sistemas informacionais capazes de atender aos usuários, deslocando-se para o diálogo direto e a mediação feita pelo bibliotecário no seu fazer diário.

Ao discutir a atuação do bibliotecário na condução da mediação em ambientes informacionais, Kuhlthau (1993) orientou cinco níveis de intervenção possíveis para o trabalho do bibliotecário como mediador no processo de busca da informação, que são:
a) Nível organizador;
b) Nível localizador/discursivo;
c) Nível identificador/instrutor;
d) Nível orientador/professor;
e) Nível tutor/conselheiro.

Para cada um desses níveis, observa-se uma postura diferente do bibliotecário perante seus usuários. No nível organizador, por exemplo, a ênfase é a organização do acervo, onde o profissional não se atém à instrução dos usuários, mas à oferta de um sistema que será explorado pelo próprio usuário.

0 mediador que se encontra no nível localizador ocupa-se em oferecer a localização daquilo que o usuário precisa num conjunto de possibilidades e fontes de informação. Esse estágio corresponde aos profissionais que atuam nos serviços de referência das bibliotecas.

Já no nível identificador, há uma intervenção maior do profissional junto ao usuário, no sentido de promover-lhe a capacitação para utilizar os recursos e ferramentas informacionais que a biblioteca lhe disponibiliza. Essa instrução pode se dar individualmente ou a grupos de usuários, mas não prevê o acompanhamento do usuário em seu processo de apropriação da informação, ou seja, “[...] os usuários tendem a pensar que basta saber identificar as fontes e operar as ferramentas para que o processo investigativo seja levado a termo [...]" (DUDZIAK, 2001, p. 125). 
84 | Nunes | Bibliotecários e documentalistas na França

No nível orientador, a ênfase do trabalho do bibliotecário recai sobre o problema do usuário, cabendo ao profissional orientá-lo na utilização sistematizada de fontes e recursos informacionais a fim de resolver seu problema em informação. Para Dudziak (2001), apesar desse nível possibilitar uma maior interação entre os bibliotecários e os docentes no sentido de prover os usuários de orientações relativas à busca, acesso, organização e uso da informação, ainda se baseia num paradigma instrucional tradicional, tal qual desenvolvido no serviço de referência.

Por fim, o bibliotecário tutor/conselheiro mostra-se envolvido com a necessidade do usuário e se ocupa não apenas em fornecer-lhe meios de acesso à informação, mas com o processo de aprendizado como um todo e que culmina com a apropriação da informação e a construção de uma nova postura com vistas a alcançar um aprendizado contínuo. Para Dudziak (2001, p. 126), essa postura aproxima-se mais da visão holística que se baseia “[...] na tríade pensamentos, sentimentos e ações". Ainda de acordo com a referida autora:

[...] 0 bibliotecário tutor/conselheiro espera que o estudante retorne periodicamente para retomar o diálogo, redefinindo o problema, determinando a estratégia, identificando fontes adicionais e sua sequência de uso, num processo dinâmico e único para cada pessoa. 0 bibliotecário tutor/conselheiro está ativamente envolvido com o currículo, estudantes, professores e administradores, em todas as formas de planejamento educacional, para gerar objetivos e metas, planejar métodos e atividade, acompanhar a evolução do estudante. (DUDZIAK, 2001, p. 126-127).

Dessa forma, a mediação dar-se-ia, conforme Davallon (2003), como a mediação pedagógica, podendo acontecer nas atividades de formação e acompanhamento de usuários, na orientação sobre percursos de pesquisa ou mesmo por meio da exposição oral e da orientação para leitura, atividades possíveis para os bibliotecários e que vão além das ações de gestão, de organização e tratamento da informação, seja no espaço das bibliotecas ou mesmo em sala de aula.

Nas bibliotecas universitárias, o bibliotecário pode e deve atuar para desenvolver a competência informacional em seus usuários, contribuindo com educadores ao desenvolverem uma visão progressista de aprendizagem e o desenvolvimento de habilidades em informação. Ao promover cursos de capacitação ou de formação dos usuários, os profissionais podem se utilizar de recursos e tecnologias educacionais e criar turmas de capacitação para o uso dos recursos informacionais, na perspectiva difundida pela American Library Association (ALA), segundo a qual o uso pleno dos recursos e 
serviços pode levar o usuário a definir melhor seus critérios de busca para chegar até a informação.

Do ponto de vista profissional, a formação de bibliotecários no Brasil teve sua origem na criação do primeiro curso de Biblioteconomia, em 1911, vinculado à Biblioteca Nacional e iniciado em 1915, tendo como parâmetro a formação francesa dos conservadores de patrimônio promovida pela École Nationale de Chartes de Paris (SOUZA, 2009). Essa primeira experiência enfatizou a formação humanística, visto que era composta por quatro disciplinas, tais como bibliografía, paleografia e diplomática, iconografia e numismática, e cujos conteúdos técnicos estavam inseridos na disciplina de bibliografia (SOUZA, 2009).

Essa influência francesa e humanística na formação do bibliotecário brasileiro estendeu-se até meados do século XX, quando cresceu fortemente a irradiação da vertente americana para a formação desse profissional e para a organização das atividades biblioteconômicas.

A influência americana provinha, dentre outros aspectos, da Escola de Biblioteconomia de Chicago e das inovações tecnológicas para os serviços de bibliotecas, como heranças da atuação marcante de Mewil Dewey, grande bibliotecário americano e criador da Classificação Decimal de Dewey (CDD) (ORTEGA, 2004).

Essa observação preliminar das origens da formação dos bibliotecários no Brasil mostra uma dualidade categórica que pode restringir a observação das demais influências na formação desse profissional. Por esse motivo, entender o fenômeno em todas as suas dimensões e complexidade requer olhar também para a formação em outros países e identificar neles as características e modalidades de formação, em especial a formação voltada para a mediação da informação desses profissionais. Dito isto, segue-se com a análise da formação dos profissionais da informação na França, um dos países que exerceu influência direta na formação do bibliotecário brasileiro.

\section{A FORMAÇÃO DO PROFISSIONAL DA INFORMAÇÃO NA FRANÇA}

\subsection{A FIGURA DO BIBLIOTECÁRIO FRANCÊS}

A formação do profissional da informação e da documentação na França compreende estatutos profissionais diferenciados, os quais englobam basicamente três Inf. Pauta, Fortaleza, CE, v. 1, n. 1, jan./jun. 2016 
86 | Nunes | Bibliotecários e documentalistas na França

profissionais: o bibliotecário, o documentalista e o professor-documentalista (CACALY et al., 2008).

Segundo Cacaly et al. (2008), a duração dos cursos pode variar de um a quatro anos, e, a depender da instituição, os programas de formação podem ser generalistas e formar profissionais no domínio da Biblioteconomia ou da Documentação, por exemplo, ao tempo em que também podem oferecer uma formação mais especializada, como documentação multimídia, criação de websites, dentre outras.

Antes de se iniciar a descrição de como se dá a formação dos profissionais da informação franceses, é preciso esclarecer como funciona o sistema educacional de ensino superior francês. E mais ainda: por que na França bibliotecários e documentalistas têm funções e formações diferentes? Por que os documentalistas são considerados os profissionais mais voltados para a informação e a mediação no domínio da CI na França?

A estrutura educacional francesa contempla estudos que vão do ensino primário (compreendido entre a escola maternal e a escola elementar) ao ensino secundário (abrangendo o colégio e o liceu). Quando conclui o ensino secundário, o candidato presta um concurso para obter o Baccalauréat (Bac), que o habilita a ingressar em uma universidade.

O ensino superior na França prevê atualmente uma formação denominada LMD, que compreende três níveis de formação: licença, mestrado e doutorado. Esse modelo permite que o estudante possa decidir sobre sua formação ao longo do processo e facilita a mobilidade entre estudantes nos países integrantes da comunidade europeia. Desse modo, e a depender da área de formação escolhida e da instituição, o aluno obtém como etapa mínima de formação superior a license, com 3 anos de estudos (Bac +3), onde adquire uma base de conhecimentos diversificada, desenvolvendo competências disciplinares, profissionais, transversais e linguísticas em vários cursos inseridos em quatro grandes domínios do conhecimento: Artes; Letras e Línguas; Direito, Economia e Gestão; Ciências Humanas e Sociais; e, por fim, Ciências, Tecnologias e Saúde. Para os que desejam ingressar diretamente no mercado de trabalho, podem cursar a license profissional, adquirida com dois anos de estudos e que confere ao candidato uma qualificação profissional.

Além da license, e para atingir um melhor nível de qualificação, os candidatos podem se preparar para ingressar em cursos de mestrado $(\mathrm{Bac}+5)$ ou doutorado $(\mathrm{Bac}+8)$. Nesses dois níveis, a ênfase recai sobre a formação de alto nível para a pesquisa e a inovação, sendo que tais títulos são requisitos de emprego para diversas áreas e o profissional que 
possui um desses títulos é bem reconhecido pelo mercado de trabalho. Sobre a formação dos profissionais da informação na França, Cacaly et al. (2008) destacam que ela foi tradicionalmente oferecida em escolas profissionais, tais como (Quadro 1):

Quadro 1 - Instituições que formam profissionais da informação na França.

\begin{tabular}{|l|c|}
\hline \multicolumn{1}{|c|}{ Instituições } & $\begin{array}{l}\text { Ano de } \\
\text { criação }\end{array}$ \\
\hline École Nationale des Chartes & 1821 \\
\hline L'EBD -École Bibliothecaires et Documentalistes & 1935 \\
\hline $\begin{array}{l}\text { L'INTD -Institut Nationale des Sciences et Techniques de la } \\
\text { Documentation }\end{array}$ & 1950 \\
\hline L'ENSB (posteriormente ENSSIB) & 1963 \\
\hline Instituts Universitaires de Technologie (IUT) & 1966 \\
\hline $\begin{array}{l}\text { L'École Nationale du Patrimoine (posteriormente l'Institut National du } \\
\text { Patrimoine) }\end{array}$ & 2001 \\
\hline
\end{tabular}

Fonte: (CACALY et al., 2008).

Para Cacaly et al. (2008, p. 29, tradução nossa), o bibliotecário é a “[...] pessoa encarregada da constituição, da gestão, de colocar à disposição do público os fundos de obras, periódicos e outros tipos de documentos (CD-Rom, fotografias, discos, etc.). Formado nas escolas profissionais e nas universidades."

Apesar de ser uma profissão antiga, os bibliotecários franceses tiveram uma maior expansão profissional a partir da segunda metade do século $\mathrm{XX}$, mais precisamente com o desenvolvimento das bibliotecas universitárias, em 1945, e com a política nacional de leitura pública, criada em 1970. Segundo Alix e Revelin (2009), essa expansão pode ser numericamente constatada quando se comparam os 198 postos de trabalho qualificados nas bibliotecas das universidades em 1945 para um número em torno de 5.700 em 2009.

Sua formação evoluiu ao longo do século XX. Conforme estudos de Bettant (2012), a École de Chartes exerceu forte influência na formação de bibliotecários franceses desde o século XIX até 1930. Com a mudança de visão a respeito da função das bibliotecas, em especial sua abertura ao público e o estímulo à leitura pública, a discussão no meio profissional ressalta sempre a necessidade de criação de uma escola especialmente dedicada à formação de bibliotecários.

Segundo Bettant (2012), os anos de 1950 e 1951 foram significativos pelas conquistas obtidas pelos profissionais bibliotecários, tais como o surgimento do Diplôme 
88 | Nunes | Bibliotecários e documentalistas na França

Supérieur de Bibliothécaire (DSB), em substituição ao Diplôme Technique de Bibliothecaire (DTB), e do Certificat d'Aptitude aux Functions de Bibliothècaires (CAFB) e a criação do Institut Nationale de Techniques Bibliothécaires (INTB), instituição que existe até os dias atuais.

Bettant (2012, p. 11) destaca quatro grandes mudanças operadas entre os anos de 1930 e 1960 para a profissão dos bibliotecários na França:

a) le passage d'un enseignement aux mains de l'École des Chartes à un enseignement supervisé par l'administration générale de la BN et la Direction des bibliothèques. Ce détachement de la tutelle de l'École des Chartes demandé régulièrement par nombre de bibliothécaires, même chartistes, fut un facteur déterminant de la modernisation de la formation; b) lié au précédent changement, le passage d'un enseignement ne s'intéressant quasiment qu'aux bibliothèques patrimoniales à un enseignement élargi à de nouveaux types de bibliothèques. Les bibliothèques pour enfants, les bibliothèques d'entreprises et les bibliothèques d'hôpitaux entrèrent peu à peu dans les programmes. La lecture publique acquérait ses lettres de noblesse, à la demande des disciples d'Eugène Morel; c) le passage d'une formation presque uniquement parisienne à une formation sur tout le territoire. Jusqu'à la fin des années 1950 pour les bibliothécaires, il n'est pas de salut hors de Paris. La formation parisienne et les stages en Sorbonne ou à la BN étaient indispensables pour réussir, et ce d'autant plus que les établissements de province ne voulaient pas s'occuper de la formation hormis quelques exceptions (La BM de Tours par exemple); d) le passage d'une formation simplement réservée aux bibliothécaires de catégorie supérieure, à une formation s'occupant aussi des personnels moins diplômés. L'apparition du CAFB montre bien qu'il n'était plus tolérable de laisser les petites et moyennes bibliothèques aux mains de personnels formés sur le tas et sans qualification. Un élargissement des formations aux métiers des bibliothèques se fit jour.

Em síntese, a formação dos bibliotecários franceses foi sendo modificada sob vários aspectos, principalmente a partir da mudança da supervisão que passou a ser exercida pela Biblioteca Nacional de França, saindo da tutela da École de Chartes. Além disso, novos modelos de bibliotecas passaram a fazer parte do rol de possibilidades de atuação dos bibliotecários franceses, tais como bibliotecas infantis, bibliotecas de empresas e bibliotecas de hospitais, inserindo-se, desse modo, nos programas de formação. A formação de bibliotecários para atuar nas pequenas e médias bibliotecas é outro aspecto observado nas mudanças da formação bibliotecária francesa apontadas por Bettant (2012).

As mudanças nos requisitos e nas atribuições dos bibliotecários, aliadas às alterações na composição do ensino superior francês, remodelaram a formação dos bibliotecários, assim como o mercado de trabalho para esses profissionais. Eles podem assumir a sua função em bibliotecas municipais ou territoriais e desenvolver suas atividades auxiliando os usuários em suas necessidades de leitura, guiando desde o público 
jovem ao grande público em suas pesquisas e desenvolvendo-lhes o gosto pelo livro e pela leitura. Executam a organização de fundos documentários e de acervos bibliográficos e são responsáveis pelas atividades de gestão e de animação dentro da biblioteca. Atualmente, as possibilidades de formação para assumir uma função pública de bibliotecário podem ser alcançadas em dois, três ou cinco anos (ONISEP, 2015):

\section{a) Formação em dois anos:}

- Com um Diplôme Universitaire de Technologie (DUT) em InformaçãoComunicação, com opção métiers livro e patrimônio.

- Com um Diplôme d'études universitaires scientifiques et techniques (DEUST), com opção métiers biblioteca e documentação, ou métiers de cultura (opção mediateca).

b) Formação em três anos:

- Com uma License professionnelle em Letras e Ciências Humanas, com opção para o trabalho com livros, edição, recursos documentários, bases de dados, gestão e tratamento de arquivos em bibliotecas, dentre outras funções, numa formação de três anos;

- Com um Diplôme de bibliothécaire documentaliste de l'EBD.

c) Formação em 5 anos:

- Mestrado profissional em Letras, Ciências Humanas e Informação-Comunicação, menção História e História da Arte, especializado em trabalhos da biblioteca e na cultura do livro.

- Com um Diplôme de conservateur de l'École des Chartes.

Quando aprovados em concurso para exercer uma função pública do Estado como bibliotecário ou conservador, os candidatos realizam uma formação profissional de 12 a 18 meses na l'École Nationale Supérieure des Sciences de l'Information et des Bibliothèques (ENSSIB). 0 curso é destinado aos bibliotecários estagiários aprovados em concurso para assumir uma função pública de Estado, ou também para os funcionários da Ville de Paris. 0 objetivo dessa formação é desenvolver competências profissionais e gerenciais aplicáveis ao conjunto de situações que os futuros bibliotecários podem enfrentar em sua carreira profissional. 
90 | Nunes | Bibliotecários e documentalistas na França

Dentre as competências previstas na formação dos bibliotecários estão as relacionadas à constituição, organização, enriquecimento, avaliação, exploração e comunicação ao público das coleções em uma biblioteca.

Para promover essa formação, um conjunto de conteúdos é oferecido num período de seis meses, além do período de estágios e elaboração de relatórios, e contempla ensinamentos de base, divididos em nove módulos temáticos (ENSSIB, 2015):

a) Conhecer e compreender seu ambiente;

b) Conceber e implantar serviços ao público;

c) Estabelecer uma política documentária dinâmica;

d) Comunicar e valorizar coleções e serviços;

e) Educar e treinar os usuários;

f) Dominar os catálogos e a indexação;

g) Digitalizar e colocar à disposição;

h) Gerenciar um projeto;

i) Gerenciar um serviço.

Observou-se que a formação proposta prevê um conjunto de conhecimentos voltados para orientar a ação do bibliotecário, seja no domínio de técnicas e recursos biblioteconômicos, seja para o desenvolvimento e disponibilização de coleções, ou para gerenciar projetos ou serviços de informação nas bibliotecas.

Um dos módulos, porém, debruça-se exclusivamente para a preparação do bibliotecário com vistas a promover a educação de usuários nas bibliotecas. Esse módulo destinado a "Ensinar e treinar eficazmente os usuários" possui 42h de carga horária e tem como objetivo levar os participantes a efetuar pesquisas em função do público e das ferramentas de referência, seja em suporte impresso ou digital. Além disso, o bibliotecário estagiário poderá desenvolver competências para desenvolver serviços de referência online, além de receber orientações sobre como criar sessões de formação de usuários nas instituições (ENSSIB, [2015]).

Com esse conjunto de conhecimentos, espera-se que o bibliotecário estagiário saiba, ao final do curso:

a) Conduzir uma entrevista de referência; 
b) Conhecer as principais fontes para a recuperação da informação;

c) Dominar a pesquisa de informações online;

d) Desenvolver sessões de treinamento de usuário.

Essas competências são consideradas fundamentais para desenvolver no bibliotecário as ações voltadas para o atendimento direto junto aos usuários e requerem conhecimentos voltados para as ações educacionais que podem ser desenvolvidas pelos profissionais nas bibliotecas. Eles são, como visto, preparados com conhecimentos mínimos para exercer essa função e, a depender de onde forem desenvolver suas atividades na instituição, podem buscar uma formação mais especializada. Na prática, outra categoria profissional passou a dividir espaço com os bibliotecários nas bibliotecas universitárias francesas: os documentalistas.

\subsection{OS DOCUMENTALISTAS COMO CATEGORIA PROFISSIONAL NA FRANÇA}

O documentalista é considerado o profissional da informação responsável por assegurar uma matriz parcial ou global da via documentária, conforme necessidades de informação identificadas. Além disso, é responsável pelo registro e pela indexação e classificação de informações em um sistema manual ou profissional, abrangendo funções em todas as etapas do processo comunicacional, que vai da pesquisa até a seleção e oferta de documentos. Pode, também, explorar o conteúdo dos documentos a partir da elaboração de documentos secundários destinados à consulta, tais como resumos, notas bibliográficas e síntese (CACALY et al., 2008).

Seu trabalho é especializado, pois se ocupa em atender às necessidades do público praticamente de modo individual, diferentemente do bibliotecário, que se ocupa em atender a grupos mais abrangentes de usuários. É possível, também, que ele seja responsável pela gestão de um centro de documentação.

Em 1945, a Union Française des Organismes de Documentation (UFOD) começou os primeiros cursos técnicos em documentação na França. Uma maior expansão da classe dos documentalistas observou-se a partir de 1950, quando foi criado o Institut National des Techniques de la Documentation (INTD), inserindo os documentalistas no ambiente profissional onde já atuavam os bibliotecários. A partir daí, os profissionais formados passaram a buscar inserção e reconhecimento no mercado de trabalho e, para tanto, Inf. Pauta, Fortaleza, CE, v. 1, n. 1, jan./jun. 2016 
criaram a Association des Anciens Élèves de l'INTD (l'AINTD), a qual gerou, em 1963, a Association Française des Documentalistes et des Bibliothécaires Spécialisés (ADBS), para fazer frente à Association des Bibliothécaire de France (ABF) (COUZINET, 2002).

Seu objetivo era fortalecer uma imagem mais dinâmica desses profissionais, em oposição à imagem dos bibliotecários, centrada na leitura pública, de formação mais generalista e voltada à conservação de patrimônio. Para essa finalidade, a ADBS tornou-se um instrumento de fortalecimento profissional, na medida em que se tornou efetivamente um espaço de difusão de técnicas e experiências profissionais e de formação de redes de cooperação, integrando teoria e prática num mesmo contexto, utilizando-se principalmente de seu veículo de comunicação: a revista Documentaliste (COUZINET, 2002).

Dentre as ações que a ADBS desenvolveu, encontram-se enquetes periódicas que visavam basicamente traçar um panorama geral da realidade dos documentalistas franceses. A primeira versão dessa enquete, publicada no primeiro número da revista Documentaliste, lançada em 1966, levantou algumas questões importantes do ponto de vista profissional sobre a situação dos documentalistas na França, chegando às seguintes conclusões:

\footnotetext{
Ela traçou um quadro de uma população em sua maioria jovem e feminina, tendo uma formação em Direito ou Letras, dividida equitativamente entre os setores público e privado. Esse grupo sofre do não-reconhecimento dos diplomas profissionais para obter um emprego nas organizações, da ausência de convenções coletivas, da falta de perspectivas de promoção, de um salário em média menor que as outras profissões em nível de qualificação equivalente. (COUZINET, 2003, p. 119, tradução nossa).
}

Os documentalistas se fortaleceram como categoria profissional no âmbito das organizações a partir da valorização das tecnologias da informação e da comunicação na década de 70 do século XX, ocupando espaços onde os bibliotecários não atuavam naquele momento, exatamente por ainda não terem se apropriado plenamente do uso das Tecnologias da Informação e da Comunicação (TIC) no âmbito profissional.

Os documentalistas que as colocam em vigor vão privilegiar a pesquisa e a difusão documentária, conceber e disponibilizar novas ferramentas como os tesauros, novos produtos como os bancos de dados, e novos conceitos aqueles de cooperação ou de redes de informação. (COUZINET, 2002, p. 59, tradução nossa).

Se a evolução do trabalho do documentalista passou pela inserção das TIC nas organizações, seu papel também evoluiu de um primeiro momento, adaptado ao manuseio 
dos bancos de dados, uso de softwares e recursos multimídia, para um outro, onde a ênfase recai sobre a análise de conteúdos e o trabalho intelectual. Foi com base no reconhecimento de sua evolução e seu papel na sociedade que os documentalistas começaram a requerer também a introdução de cursos de formação voltados para a documentação nas universidades. Assim, a partir de 1966, foram criados departamentos voltados às carreiras de documentação nos Instituts Universitaires de Technologie (IUT).

Atualmente, para alcançar a formação nessa área, os profissionais buscam obter um Diplôme Universitaire en Tecnologie (DUT) em Documentação, numa formação em dois anos $(\mathrm{Bac}+2)$. Essa certificação é oferecida por meio dos IUT espalhados pelo país, que ofertam essa formação na grande área de Informação-Comunicação. Além disso, outras escolas se ocupam da formação de documentalistas na França, tais como o Institut National des Sciences et Techniques de la Documentation (INTD) e a École des BibliothécairesDocumentalistes (EBD).

Dentre as missões e atividades desempenhadas pelos documentalistas podem-se destacar (Quadro 2):

Quadro 2 - Missão e atividades dos documentalistas na França.

\begin{tabular}{|c|c|}
\hline Missão & Atividades \\
\hline $\begin{array}{l}\text { - Definir uma política de gestão da informação. } \\
\text { - Adquirir e utilizar ferramentas adaptadas às } \\
\text { necessidades dos usuários. } \\
\text { - Analisar, tratar e explorar a informação e os } \\
\text { recursos a fim de torná-los acessíveis e colocá- } \\
\text { los à disposição dos usuários. } \\
\text { - Difundir a informação através de produtos } \\
\text { documentários adaptados. } \\
\text { - Formar os usuários para as metodologias de } \\
\text { pesquisa a fim de torná-los mais autônomos. }\end{array}$ & $\begin{array}{l}\text { - Pesquisa e seleção da informação, depois } \\
\text { tratamento e difusão. } \\
\text { - Tratamento da informação aos meios e } \\
\text { técnicas documentárias. Elaborar e manter } \\
\text { ferramentas de classificação e indexação. } \\
\text { - Difundir a informação: concepção, realização } \\
\text { de produtos e serviços documentários } \\
\text { adaptados às necessidades dos usuários, } \\
\text { publicação de conteúdos web. } \\
\text { - Fluxo documentário: explorar e gerir } \\
\text { informação da imprensa, seguida dos fluxos } \\
\text { de informação. } \\
\text { - Gerir os fundos documentários: aquisição e } \\
\text { assinaturas, classificação desses fundos, } \\
\text { fornecer acesso aos documentos, } \\
\text { parametrizar e alimentar os programas } \\
\text { documentários, negociar junto aos editores } \\
\text { das bases de dados. } \\
\text { - Formar os usuários para as metodologias de } \\
\text { pesquisa a fim de torná-los mais autônomos. } \\
\text { - Escolha das ferramentas e das bases de dados } \\
\text { em função das necessidades dos usuários e } \\
\text { dos meios postos à disposição. } \\
\text { - Acolhimento e ajuda aos usuários. } \\
\text { - Pode gerir os arquivos e as informações } \\
\text { produzidas pelas empresas. }\end{array}$ \\
\hline
\end{tabular}


Nos IUT, a formação do documentalista se desenvolve em quatro semestres, e a inserção profissional dependerá da escolha de cada aluno por uma atuação específica no campo das Sciences de l'Information et de la Comunication (SIC). Para tornar-se professordocumentalista, o candidato deve preparar-se para obter o Certificat d'Aptitude au Professorat de l'Enseignement du Second Degré (CAPES), que lhe confere a certificação necessária a ministrar cursos de documentação nas escolas de second degrée. A preocupação com a formação de professores-documentalistas está diretamente relacionada à formação de pessoal para o ensino e a pesquisa em SIC na França. Em muitos casos, outros profissionais têm se ocupado dessa função, sem, contudo, terem obtido uma formação dentro dos fundamentos teórico-metodológicos da SIC, e mais particularmente da documentação, o que gera desconforto por parte dos pesquisadores da área.

Para Cunha (1999), essa diversidade nos níveis de formação possui como vantagens a garantia à formação continuada dos profissionais, definida pelo governo francês, mas também desvantagens, como a falta de discussão mais aprofundada para a criação de novas formações e a carência de candidatos a se lançarem na formação para a pesquisa, o que gera uma defasagem em relação à necessidade de mais pesquisadores que fortaleçam as pesquisas em SIC.

\section{CONSIDERAÇÕES FINAIS}

A partir dos conteúdos teóricos apresentados, podem-se identificar os aspectos que cercam a formação dos profissionais da informação na França. São profissionais com estatutos diferentes, cujas especificidades refletem características profissionais diversas, mas se observou também que a mediação da informação ainda não é uma temática central na formação para atuação nas bibliotecas francesas.

Quando se pensa na construção disciplinar para a formação do profissional da informação voltada para a mediação, espera-se que um conjunto de disciplinas e conteúdos sejam oferecidos no sentido de fazê-lo compreender essa função em todas as atividades que ele pode vir a desempenhar numa unidade de informação. Na prática, isso não é uma constante, mas ocorre de modo esporádico e depende da direção que os professores dão às disciplinas e do enfoque que é dado em relação aos conteúdos e às leituras exigidas. 
Por esse motivo, analisando-se a perspectiva francesa de formação, onde bibliotecários e documentalistas disputam espaço e reconhecimento profissional, é possível perceber também que ambas as profissões tiveram uma evolução maior ao longo do século XX, e as especificidades analisadas nos dois casos podem oferecer subsídios para compreender os aspectos que levaram à construção do profissional da informação no Brasil como categoria profissional. Esses aspectos podem coincidir com as mudanças em nível profissional operadas no Brasil, com vistas a estabelecer a figura do moderno profissional da informação que hoje ocupa as unidades de informação.

Essas são perspectivas a serem consideradas e que pretendem destacar a importância do profissional da informação no contexto brasileiro e sua formação a partir da contribuição de vertentes estrangeiras do campo da CI.

\section{REFERÊNCIAS}

ALIX, Yves; REVELIN, Gaël. Les bibliothécaires, combien de divisions? Rencontre sur les lieux d'échange et de débat de la profession. Bulletin des bibliothèques de France [en ligne], n. 4, 2009. Disponível em: <http://bbf.enssib.fr/consulter/bbf-2009-04-0017-002>. Acesso em: 16 abr. 2015.

ALMEIDA JÚNIOR, Oswaldo Francisco de. Mediação da informação e múltiplas linguagens. Pesq. Bras. Ci. Inf., Brasília, v. 2, n. 1, p. 89-103, jan./dez. 2009.

BETTANT, Audry. Histoire de la formation du bibliothécaire: du DTB à l'ENSB 19321963). 2012. 97 f. Memoire (Diplome de Conservateur de Bibliothèque) - Université de Lyon, ENSSIB, 2012.

CACALY, Serge et al. (Org.). Dictionnaire encyclopédique de l'information et de la documentation. 3. ed. Paris: Armand Colin, 2008.

COUZINET, Viviane. Expertise et association professionelle: de la reconaissance des documentalistes. Questions de comunication, v. 2, p. 57-69, 2002.

. Praticiens de l'information et chercheurs: parcous, terrains et étayages.

Documentaliste - Sciences de l'Information, v. 40, n. 2, p. 118-125, 2003.

CUNHA, Miriam Vieira. A Formação em Ciência da Informação na França, no Canadá e na Dinamarca: comparação com o Sistema Brasileiro. Enc. Bibli: R. Eletr. Bibliotecon. Ci. Inf., Florianópolis, Brasil, n. 8, p. 20-27, 1999.

DAVALLON, Jean. La médiation: la comunication en procès? MEI, Médiation et Information, n. 19, p. 37-59, 2003. 
DUDZIAK, Elizabeth Adriana. A information literacy e o papel educacional das bibliotecas. 2001. 187 f. Dissertação (Mestrado em Ciências da Comunicação) - Escola de Comunicação e Artes, Universidade de São Paulo, São Paulo, 2001.

EDB. École des bibliothécaires documentalistes. Disponível em:

<http://www.ebd.fr/ewb_pages/c/contenusfi.php>. Acesso em: 10 maio 2015.

ENSSIB. École nationale supérieure des sciences de l'information et des bibliothèques. Formation des bibliothécaires. Disponível em: <http://www.enssib.fr/formation/formation-des-bibliothecaires>. Acesso em: 10 maio 2015.

KUHLTHAU, Carol C. A principle of uncertainty for information seeking. Journal of Documentation, v. 49, n. 4, p. 339-355, 1993.

ONISEP. L'Info nationale et régionales sur les métiers et les formations. Disponível em: <http://www.onisep.fr/Ressources/Univers-Metier/Metiers/bibliothecaire > . Acesso em: 7 maio 2015.

ORTEGA, Cristina Dotta. Relações históricas entre Biblioteconomia, Documentação e Ciência da Informação. DataGramaZero: Revista de Ciência da Informação, v. 5, n. 5, out./2004. Disponível em: <http://www.dgz.org.br/out04/Art_03.htm>. Acesso em: 6 out. 2013.

SMIT, Johanna W.; BARRETO, Aldo de Albuquerque. Ciência da Informação: base conceitual para a formação do profissional. In: VALENTIM, Marta Lígia Pomim (Coord.). Formação do profissional da informação. São Paulo: Polis, 2002. p. 9-24.

SOUZA, Francisco das Chagas de. Ensina-se corretamente o que se ensina a quem vai ser bibliotecário? Revista ACB: Biblioteconomia em Santa Catarina, Florianópolis, v. 1, n. 1, p. 49-54, 1996.

. 0 impacto da atuação da ABEBD na evolução do currículo de graduação em Biblioteconomia no Brasil, entre os anos 1967 e 2000. Relatório de Pesquisa desenvolvida com apoio financeiro do CNPq (Processo no 473200/2006-6, de outubro de 2006 a setembro de 2008).

UFSC, 2009.

0 ensino de Biblioteconomia no contexto brasileiro: Século XX. Florianópolis: Ed.

VARELA, Aida Varela; BARBOSA, Marilene Abreu. A multirreferencialidade de saberes nos atos de mediação do conhecimento: o aporte das ciências cognitivas à ação pedagógica das bibliotecas. Perspectivas em Ciência da Informação, v. 14, n. 2, p. 187-203, maio/ago. 2009. 


\section{SOBRE A AUTORA}

\section{Martha Suzana Cabral Nunes}

Professora do Departamento de Ciência da Informação da Universidade Federal de Sergipe. Doutora em Ciência da Informação pelo PPGCI/UFBA.

E-mail: marthasuzana@hotmail.com

Recebido em: 01/05/2016; Revisado em: 17/06/2016; Aceito em: 20/06/2016.

\section{Como citar este artigo}

NUNES, Martha Suzana Cabral. Bibliotecários e documentalistas na França: a busca pelas origens da formação do profissional da informação. Informação em Pauta, Fortaleza, v. 1, n. 1, p. 79-97, jan./jun. 2016. 